\title{
GESTÃO DA INFORMAÇÃO E DO CONHECIMENTO NAS ORGANIZAÇÕES E A ORIENTAÇÃO DE MARKETING
}

\author{
GESTIÓN DE INFORMACIÓN Y DEL CONOCIMIENTO EN LAS ORGANI- \\ ZACIONES Y LA ORIENTACIÓN DE MARKETING
}

\begin{abstract}
Sueli Angelica do Amaral - samaral@unb.br
Doutora em Ciência da Informação pela Universidade de Brasília. Professora Associada do Departamento de Ciência da Informação e Documentação da Universidade de Brasília
\end{abstract}

\section{Resumo}

Comenta os aspectos da comunicação, da administração e da tecnologia da informação em relação aos processos de gestão da informação e gestão do conhecimento na ótica da Ciência da Informação, a partir da ênfase à importância da informação e do conhecimento no contexto da sociedade da informação e do conhecimento. Discute a necessidade de entender o negócio da informação na ótica de marketing e mostra de forma esquemática a oferta de produtos e serviços de informação no ambiente tradicional e na web no contexto do mercado da informação onde atuam os diversos atores sociais do negócio da informação. Apresenta os princípios de marketing a serem seguidos pela unidade de informação orientada para o marketing, como sugestão para a sobrevivência da biblioteca do futuro, em conformidade com os requisitos exigidos pelos novos consumidores da sociedade da informação e do conhecimento.

\section{Palavras-chave}

Gestão da informação; Gestão do conhecimento; Orientação de marketing; Oferta de informação; Demanda de informação. 


\section{INTRODUÇÃO}

Para discorrer sobre a gestão da informação e do conhecimento nas organizações e a orientação de marketing, é preciso situar essa abordagem no âmbito da Ciência da Informação.

Nesse sentido, apresenta-se discussão sobre a importância da informação e do conhecimento no contexto da sociedade da informação e do conhecimento, para então comentar aspectos da Comunicação, da Administração e da tecnologia em relação aos dois processos, o de gestão da informação e o de gestão do conhecimento na ótica da Ciência da Informação.

A partir dessa abordagem, discutese a necessidade de entender o negócio da informação na ótica de marketing, ao contextualizar de forma esquemática a oferta e a demanda de informação no ambiente tradicional e na web sob o ponto de vista da orientação de marketing no mercado da informação, onde atuam os diversos atores sociais do negócio da informação.

Ao final, apresentam-se os princípios de marketing a serem seguidos pela unidade de informação que atue sob a orientação de marketing. Assim, sugere-se que a biblioteca do futuro poderá sobreviver com maiores possibilidades de sucesso no atendimento e no seu relacionamento com os usuários como consumidores e parceiros no planejamento da oferta dos produtos e serviços de informação de modo a atender satisfatoriamente a demanda desses novos usuários no contexto da sociedade da informação e do conhecimento.

\section{IMPORTÂNCIA DA INFORMAÇÃO E DO CONHECIMENTO}

Vivemos um momento de impacto, diante do que chamamos de sociedade da informação e do conhecimento. Não se trata de uma era de máquinas inteligentes, mas de seres humanos que, por meio das redes, podem combinar sua inteligência, conhecimento e criatividade para conseguir grandes avanços na criação de riqueza e de desenvolvimento social.

São tempos de globalização da economia, política buscando novos caminhos calcados nos valores humanos, gestão da qualidade total, concorrência acirrada, privatizações, valorização do código de defesa do consumidor, aperfeiçoamento evolutivo das tecnologias aplicadas à informação, crescimento exponencial e obsolescência da informação, múltiplas e diversificadas necessidades de informação dos usuários.

Na sociedade do conhecimento, a informação, gerando ação (conhecimento), 
constitui o mais importante recurso de agregação de valor. Sua versatilidade permite atender às necessidades do consumidor de forma muito mais satisfatória. O conhecimento revoluciona o processo de produção, uma vez que ele torna economicamente viável a individualização e diversificação de produtos. A evolução do tempo exige cada vez mais regras e conhecimentos específicos. A inovação, que consiste em trabalho árduo e sistemático de análise periódica dos produtos, serviços, tecnologia, mercado e canais de distribuição é o que determinará a sobrevivência das organizações (BORGES, 1995).

A vida humana está condicionada de tal maneira à informação, que esta pode ser considerada como necessidade primária. Cornelsen (1999) afirma que a informação não é um tema recente. Ela sempre existiu e é inerente ao homem, logo, o homem que possui mais informação tem mais armas para sobreviver e para adaptar-se ao meio que habita.

Percebe-se também que por meio da comunicação ocorrem as trocas, as transmissões, os fluxos de informação, as interações e as ligações entre os indivíduos. Assim, pode-se afirmar que não há comunicação sem informação. A comunicação é o processo, o mecanismo, a ação e a informação é a matéria, o produto que será comunicado. $O$ papel da comunicação é transmitir informação (LE COADIC, 1996). Portanto, a interdependência da comunicação e da informação é tão forte que Davis (1967) definiu comunicação como o processo de passar informação e compreensão de uma pessoa para outra.

A função de informar só é exercida se houver informação. A comunicação não ocorrerá a menos que alguém adquira e consuma alguma informação a respeito de si mesmo e do seu meio ambiente. Logo, a informação é básica para todas as outras funções aplicadas da comunicação (THAYER, 1972).

A partir dessa visão, a informação passa a ser matéria-prima da Comunicação e os estudiosos dessa área também se consideram profissionais da informação. Então, a própria denominação da Ciência da Informação entra em questão. Existem os defensores da sua denominação no plural: Ciências da Informação.

Nesse contexto, o discurso sobre a importância e valorização da informação e do conhecimento é lugar comum na literatura de muitas áreas, como Ciência da Informação, Administração, Comunicação, Educação, Sociologia, Tecnologia da Informação, entre outras. É fácil entender esse enfoque, pois a informação, além de ser o insumo básico para geração de conhecimento, todo ser humano durante a sua existência precisa de informação para 
tudo. Seja na área pessoal, nos negócios, na academia, nada se faz sem informação. Tudo depende dela. Sendo assim, por conseqüência, é importante também a sua gestão.

Como a gestão é domínio da Administração, muitos estudos e pesquisas nessa área do conhecimento incluem os aspectos de interesse da gestão da informação. Não se discute a legitimação desse fato. Pelo contrário, chama-se a atenção também para outro fato. Com a mesma justificativa de o domínio da gestão estar inserido no âmbito de sua área, a Administração se apropria dos estudos e pesquisas sobre a gestão do conhecimento, sem a preocupação epistemológica ou conceitual sobre o conhecimento em si ou da impossibilidade do seu gerenciamento, uma vez que é possível aceitar que o conhecimento estaria na cabeça das pessoas. Além disso, até mesmo este argumento pode ser combatido, pois a gestão de pessoas também é domínio da área. Portanto, tratam-se de abordagens pertinentes ao escopo da Administração. Essa afirmativa é confirmada, na estrutura dos eventos promovidos no âmbito da Associação Nacional de Pós-Graduação e Pesquisa em Administração (ANPAD). No principal evento da ANPAD, o ENANPAD uma das divisões acadêmicas (ADI) reúne os trabalhos sobre Administração da
Informação e uma área dessa divisão é específica para Gestão da Informação e do Conhecimento. Ademais, a partir de 2007, a ANPAD passou a realizar o ENADI, que é um encontro específico para apresentação dos trabalhos da divisão acadêmica sobre Administração da Informação. São iniciativas legítimas e pertinentes ao escopo da Administração.

O mundo dos negócios ainda está começando a descobrir o que os bibliotecários e profissionais da informação sempre souberam: sem instrumentos de auxílio à pesquisa e contexto, a informação é inútil.

Estamos migrando da era da computação para a era da conectividade, do físico para o integrado. Os competidores incorporam tecnologia em tudo: telefones, computadores pessoais, ipod, gravadores. Trata-se de uma integração contínua que Ihes permite estar em contato permanente. Isso traz implicações para o compartilhamento.

Os indivíduos agora compartilham conhecimento, capacidade computacional, largura de banda e outros recursos para criar uma vasta gama de bens e serviços gratuitos e de código aberto, que qualquer um pode usar ou modificar. Isso está fazendo surgir novas capacidades colaborativas e modelos de negócios, que darão poder às empresas bem preparadas e des- 
truirão aquelas que não forem capazes de se adaptar.

Na oferta de produtos e serviços de informação, a adoção de novas tecnologias da informação e comunicação (TICs) tornou-se imperativa para que o acesso à informação pudesse acontecer além das paredes das bibliotecas, como organizações provedoras de informação, tanto no seu ambiente tradicional de prestação de serviços, como por meio dos seus websites, que passaram a representar as bibliotecas no ambiente web da Internet. As bibliotecas precisaram mudar sua forma de atuar, adotando as novas TICs disponíveis para ampliar o acesso à informação. Além das bibliotecas, também precisaram mudar sua forma de atuar os outros setores ou unidades organizacionais responsáveis pela oferta de produtos e serviços de informação, denominados centros de informação/documentação, de multimídias e outras unidades organizacionais similares que usam diversas denominações de acordo com o seu contexto ou extensão de atividades desenvolvidas.

Os procedimentos técnicos para a seleção, organização, catalogação, classificação, indexação, armazenamento e recuperação da informação para o seu uso pelos usuários também se modificaram a partir da adoção das novas tecnologias disponíveis. A tecnologia passou a ser indispensável para dar conta dos processos técnicos do tratamento da informação. Por outro lado, a evolução tecnológica aconteceu de forma muito acelerada. Isso fez com que o acompanhamento dessa evolução pelos provedores de serviços de informação ficasse descompassado. Ao mesmo tempo em que os profissionais responsáveis pelos procedimentos técnicos relativos ao tratamento, processamento e recuperação da informação aprendiam sobre as novas tecnologias e as empregavam, outras novas tecnologias surgiam.

Esta situação talvez possa nos levar a entender $\mathrm{O}$ comportamento dos profissionais da área de Tecnologia da Informação. Os tecnólogos se apropriaram da informação, embora o seu domínio seja a tecnologia. Dessa forma, a Tecnologia da Informação se agigantou, expandiu-se, em detrimento do seu conhecimento sobre a informação em si. Como a informação não pode ser vista sem a tecnologia, de um modo geral nas organizações, o profissional e a unidade de informação ficam em segundo plano na perspectiva tecnológica da organização. É comum verificar nas organizações, maior ênfase aos profissionais da área da tecnologia do que aos profissionais da informação. 
Essas mudanças, entre outras, estão abrindo caminho em direção a um novo mundo, onde a criação de valor será rápida, fluida e, persistentemente, perturbadora.

\section{E A CIÊNCIA DA INFORMAÇÃO?}

É incontestável afirmar que a Ciência da Informação é uma ciência inter, multi e transdisciplinar. Estudos epistemológicos sobre essa ciência vêm sendo desenvolvidos e discutidos pelos interessados nessa temática. Uma das definições de Ciência da Informação, embora apresentada por Borko (1968) na década de 1960, é apreciada por muitos, apesar de decorridas quatro décadas de sua apresentação. Para ele, a Ciência da Informação investiga as propriedades e o comportamento da informação, as forças que regem o fluxo informacional e os meios de processamento da informação para otimização do acesso e uso. Está relacionada com um grupo de conhecimento que abrange a origem, coleta, organização, armazenamento, recuperação, interpretação, transmissão, transformação e utilização da informação. Isto inclui a investigação, as representações da informação, tanto no sistema natural, como artificial, o uso de códigos para uma eficiente transmissão de mensagens e o estudo dos serviços e técnicas de processa- mento de informação e seus sistemas de programação.

Trata-se de uma ciência interdisciplinar derivada e relacionada com vários campos como a matemática, a logística, a lingüística, a psicologia, a tecnologia computacional, as operações de pesquisa, as artes gráficas, as comunicações, a biblioteconomia, a gestão e outros campos similares. Tem tanto um componente de ciência pura, que indaga o assunto sem ter em conta a sua aplicação, como um componente de ciência aplicada, que desenvolve serviços e produtos. A biblioteconomia e a documentação são aspectos aplicados da ciência da informação (BORKO, 1968).

A definição de Borko (1968) nos leva a aceitar a prática da gestão no campo de atuação da Ciência da Informação, embora possa ser interpretada como restrita à gestão da informação.

No âmbito da Associação Nacional de Pesquisa e Pós-Graduação em Ciência da Informação (ANCIB), a gestão da informação e do conhecimento nas organizações é o tema central de um dos grupos de trabalho e pesquisa. Essa temática também identifica uma das linhas de pesquisa de dois Programas de Pós-Graduação em Ciência da Informação, com cursos de mestrado e doutorado, o da Universidade de Brasília e o da Universidade Federal de 
Minas Gerais, que estudam a Gestão da Informação e do Conhecimento.

Embora a gestão da informação e a gestão do conhecimento estejam delineadas no âmbito da Pós-Graduação e da Pesquisa na área da Ciência da Informação, percebe-se que essas temáticas são emergentes e necessitam ampliar o seu entendimento, suas definições e seu escopo, principalmente para diferenciar esses dois processos de gestão, no âmbito dessa Ciência.

Quando se pensa em Ciência Política ou Ciências Sociais, relacionam-se a essas ciências, o cientista político e o cientista social. Porém, a sociedade não entende o cientista da informação como um estudioso ou pesquisador da área de Ciência da Informação. As pessoas, de um modo geral relacionam Ciência da Informação com computador e Informática. $\mathrm{O}$ discurso extremamente tecnicista e $\mathrm{O}$ jargão da Biblioteconomia implícitos na origem da Ciência da Informação caracterizam uma ciência de escopo indefinido, de cujo domínio as outras ciências se apropriam.

A informação, como insumo para o conhecimento deveria ser defendida como objeto de estudo da área. Como na área não há consenso nem mesmo para a definição de informação, por conseqüência, os estudos e pesquisas sobre comunicação da informação, tecnologia da informação e sobre gestão da informação e do conhecimento na ótica da Ciência da Informação ainda são incipientes tanto nas suas abordagens qualitativas quanto quantitativas. Trata-se de uma ciência em busca da conquista do seu espaço no âmbito das Ciências Sociais Aplicadas.

Assim, percebe-se que a transdisciplinaridade da área da Ciência da Informação é um aspecto ainda não resolvido na área, que se reflete no desconhecimento da sociedade em geral do que seja essa ciência, bem como na falta de visibilidade do seu domínio e do campo de atuação dos seus estudiosos e pesquisadores, de um modo geral.

\section{GESTÃO DA INFORMAÇÃO E DO CO- NHECIMENTO NAS ORGANIZAÇÕES}

Seja qual for a prática da gestão da informação e do conhecimento nas organizações, essas práticas refletirão a cultura organizacional e a política de informação adotadas pela organização e revelarão a importância da informação e do conhecimento como recursos estratégicos de sobrevivência organizacional (CHOO, 2006).

Portanto, descrever, decodificar significados de fenômenos relacionados aos processos de gestão da informação e do conhecimento são tarefas complexas, que envolvem os mais diversificados ambientes 
organizacionais. Isto significa que, é preciso considerar a diversidade contextual, mas ao mesmo tempo identificar convergências e semelhanças que possam nortear certo grau de generalização.

Para Beijerse (2000), o gerenciamento de conhecimento é o gerenciamento de informações dentro de uma organização pelo direcionamento da estratégia, estrutura, cultura e sistemas, capacidades e atitudes das pessoas com relação a seus conhecimentos. Complementa sua afirmativa, com a premissa de que o gerenciamento do conhecimento atinge as metas da organização, por tornar produtivos os fatores de conhecimento. Defende essa premissa, pois isto é feito primeiramente pela facilitação e motivação das pessoas para extraírem e desenvolverem as suas capacidades (suas competências essenciais) e para estimular suas atitudes para intraempreender.

Além disso, no ponto de vista de Beijerse (2000), o gerenciamento de conhecimento inclui a totalidade dos sistemas com os quais as informações dentro das organizações podem ser gerenciadas e abertas. Ele organizou um modelo de gestão do conhecimento, com o objetivo de tornar o fator conhecimento produtivo, considerando o nível operacional, tático e estratégico, a partir da estratégia, estrutura, cultura e sistemas da organização.
No modelo de Beijerse (2000), os domínios do conhecimento compreendem: organização, marketing e tecnologia. O conhecimento relacionado com a organização abrange: gerenciamento, política, cultura, pessoal, planejamento da carreira, processos internos, reduções, alianças e trabalho em equipe. O conhecimento de marketing diz respeito a: concorrentes, fornecedores, clientes, mercados, metas de grupos, consumidores, usuários, partes interessadas, vendas, pós-vendas, negócios, distribuição e gerenciamento de relacionamento. Já o conhecimento tecnológico considera: produtos, pesquisa e desenvolvimento, competências essenciais, desenvolvimento tecnológico, informação e tecnologia de comunicações, desenvolvimento de produtos e montagem.

Entretanto, Beijerse (2000) enfatiza que a realidade deve ser considerada, pois, obviamente, nem sempre é a mesma do contexto estudado. O modelo conceitual somente dá diretrizes para importantes itens com relação ao gerenciamento do conhecimento, onde tornar o fator conhecimento produtivo é a meta final; a informação é gerenciada e aberta; as competências essenciais dos empregados são extraídas e desenvolvidas; e o intraempreendedorismo das pessoas é estimulado.

Portanto, para colocar em prática o modelo proposto por Beijerse (2000), o 
profissional que trabalha em unidades de informação precisa entender que a informação não pode ser considerada somente como um bem econômico, uma vez que não se limita a um simples produto ou matéria-prima de uso doméstico. A informação deve ser estudada como fator essencial que permite o salto para a verdadeira transformação da sociedade. Quando uma sociedade evolui, ocorre a transformação advinda da mudança de foco em relação aos fatores de produção e desenvolvimento econômico. A base dessa transformação é que o setor de informação, no qual se inserem as bibliotecas e demais unidades de informação, é intensivo em conhecimento e não em mão-de-obra. O valor agregado do conhecimento é progressivamente mais importante e incorporado ao bem, provocando a transformação industrial da matéria-prima informação em valor agregado.

A informação é o insumo de fundamental importância na geração de conhecimento, ao impulsionar o desenvolvimento da sociedade. Como desenvolver qualquer atividade ou empreendimento, qualquer que seja o cenário do trabalho, sem dispor de informações?

\section{ORIENTAÇÃO DE MARKETING E CIÊNCIA DA INFORMAÇÃO}

Sabe-se que entre estudiosos e pesquisadores da Ciência da Informação a resistência à adoção das técnicas de marketing é fato. Mas, apesar dessa forte rejeição, paradoxalmente, afirma-se, com muita freqüência que é preciso fazer o "marketing da biblioteca" ou que o problema da falta de visibilidade do setor de informação resulta da falta de marketing. Também é comum, até mesmo apontarem o marketing como vilão. Entretanto, em paralelo, bibliotecários e outros profissionais da informação buscam os ensinamentos de marketing para aplicá-los na gestão da informação e do conhecimento, com a intenção de assegurar melhores condições de desempenho e sucesso. Muitas são as razões que podem explicar esse comportamento, mas a principal delas é a associação do marketing a vendas e a limitação do marketing à promoção (AMARAL, 2008).

Marketing não é apenas vender e também não começa com os produtos e serviços. Marketing começa com o cliente. Não é propaganda e pensar só em fazer dinheiro, nem mesmo para as organizações que recebem dinheiro pelos seus produtos.

A principal meta da orientação de marketing é auxiliar as organizações a atingirem seus objetivos. No caso de empresas privadas, o objetivo maior é o lucro; 
no caso de organizações sem fins lucrativos e órgãos públicos é sobreviver e atrair recursos suficientes para desempenhar um trabalho útil. Apesar desse fato, as empresas privadas não devem puramente objetivar lucros, mas alcançar lucros como conseqüência da criação de valor superior para o cliente. Uma empresa ganha dinheiro ao satisfazer as necessidades dos clientes melhor do que a concorrência o faz (KOTLER, 2000).

Marketing é bom senso aplicado ao negócio de provisão de produtos e serviços aos clientes, a partir da identificação das necessidades desses clientes e do planejamento e gestão da oferta para atendêlos. É preciso focalizar o que se faz, para quem se faz e porque se faz.

De acordo com a American Marketing Association (2004), marketing é um processo gerencial. Trata-se de uma função social e um conjunto de processos que envolvem a criação, a comunicação e a entrega de valor para os clientes, bem como a administração do relacionamento com eles, de modo que beneficie a organização e o seu público interessado.
A definição de marketing da American Marketing Association (2004) e a de Ciência da Informação apresentada por Borko (1968) facilitam a aceitação da possibilidade de associar o marketing à Ciência da Informação. Isto porque, Borko (1968) admite que a Ciência da Informação seja uma ciência interdisciplinar relacionada, entre outros campos, com o da gestão. Como o marketing é uma abordagem do processo gerencial, seu estudo está, conseqüentemente, relacionado com a Ciência da Informação, no que diz respeito à gestão da informação e do conhecimento.

A orientação de marketing determinará a atuação no processo de trocas da organização com o seu meio ambiente, sempre levando em conta a satisfação do consumidor. A função do marketing é a sua tarefa genérica, isto é, o conjunto de técnicas desenvolvidas com o objetivo de facilitar a realização de trocas. O elenco das atividades do processo de gestão, incluindo o planejamento, a organização, a direção e o controle, deve estar alinhado ao conceito ou mentalidade de marketing, que é a dimensão filosófica atribuída ao marketing pela organização, conforme esquematizado na Figura 1. 


\section{AS TRÊS DIMENSÕES}

\section{DO MARKETING}

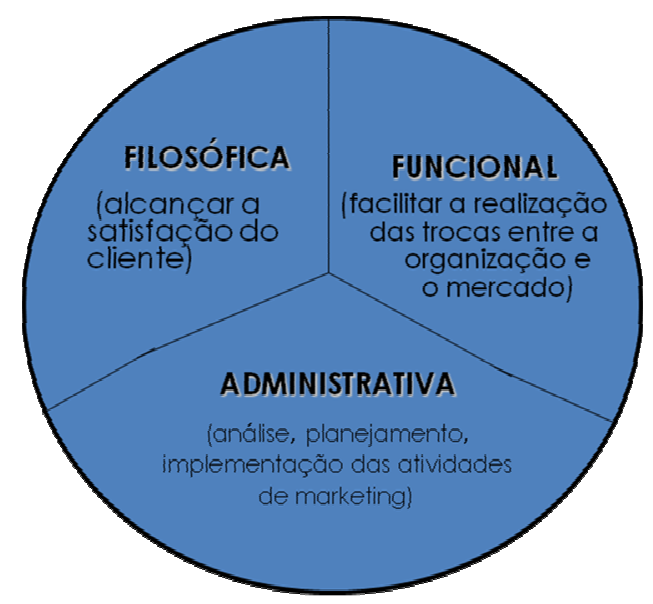

Figura 1 - As três dimensões do marketing

Cada organização pode atribuir uma importância diferente e conduzir as atividades de marketing de forma distinta, dependendo de sua filosofia de ação.

A filosofia de atuação da unidade de informação orientada para o marketing volta-se para o atendimento e o relacionamento com a clientela, com ênfase na função de troca, mediante ações administrativas, visando os objetivos organizacionais.

A ênfase nos princípios de marketing pressupõe: (a) comprometimento com a filosofia de marketing adotada pelos gestores da alta direção da organização; (b) suporte administrativo da alta direção; (c) desenvolvimento das atividades com foco no cliente; (d) preocupação com o atendimento, receptividade às crí- ticas, reclamações e sugestões; (e) divulgação dos benefícios advindos da adoção das técnicas de marketing; e acima de tudo (f) destaque para o relacionamento entre a organização e seus públicos.

A orientação de marketing pressupõe a mudança de atitude profissional, conhecimento técnico, comprometimento da alta direção, treinamento de pessoal e muito planejamento e gestão.

Dessa forma, a adoção das técnicas de marketing pelas unidades de informação corresponderá à visão do mercado da informação no contexto do negócio da informação, que só poderá ser obtida quando são reconhecidos os princípios conceituais e filosóficos do marketing. 
Na figura 2 podem ser observados os diversos atores sociais do mercado da informação e de forma esquemática entender o negócio, onde se inserem as bibliotecas e demais unidades de informação, como organizações responsáveis pela provisão da oferta de produtos e serviços de informação no ambiente tra- dicional e no ambiente web da Internet. Esta oferta de informação deve atender satisfatoriamente a demanda dos usuários da informação. Para isso, deve identificar e entender os requisitos de exigência dos novos consumidores da sociedade da informação e do conhecimento.

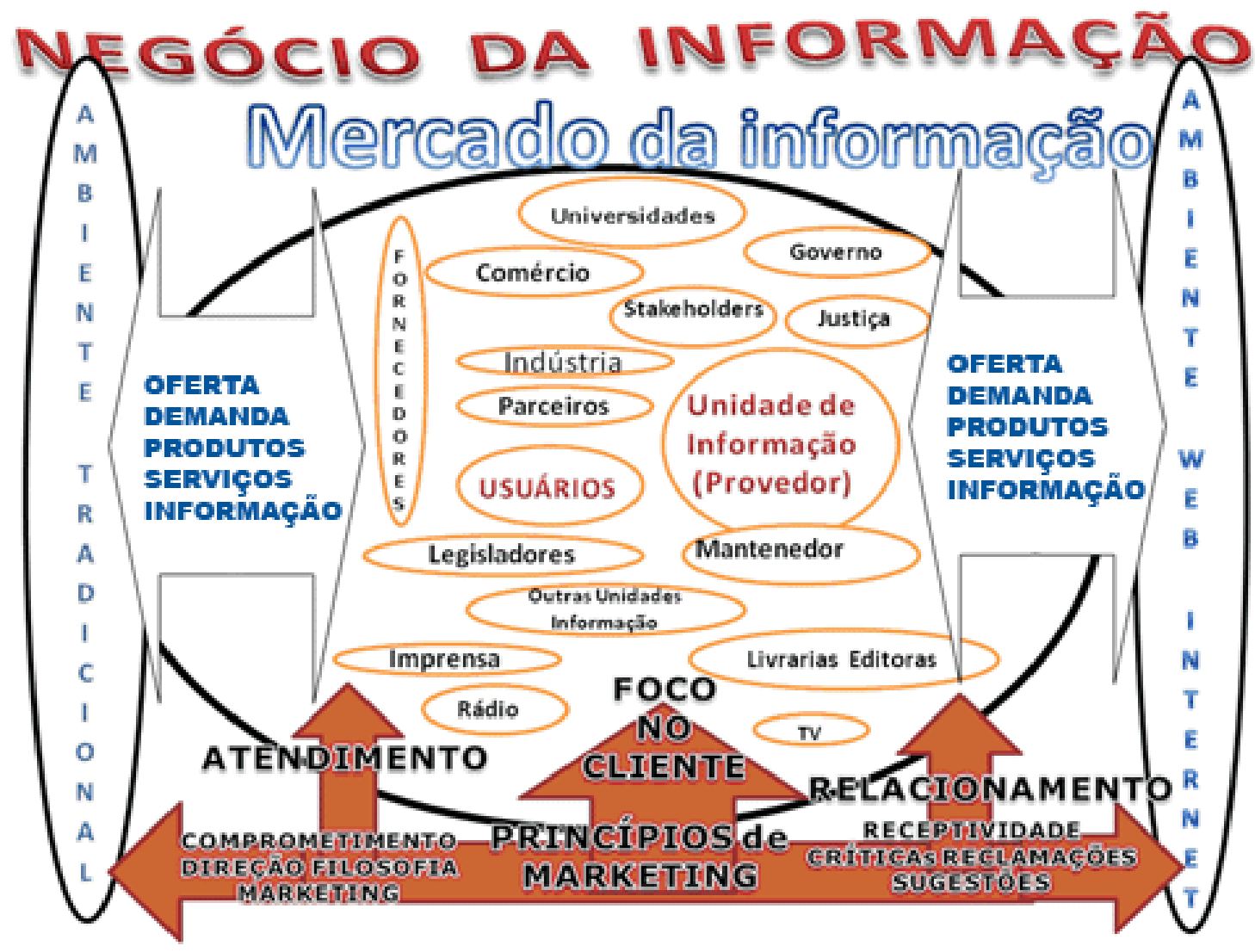

Figura 2 - Negócio da Informação

É nesse cenário que se desenvolvem os processos de gestão da informação e do conhecimento nas organizações. Será que a gestão da informação e do conhecimento nessas organizações é desenvolvida sob a ótica do negócio da informação? Os profissionais responsá- veis pela oferta de informação, em especial os gestores, são capazes de exercer a gestão da informação e do conhecimento nas organizações em que atuam, de modo a satisfazer a demanda informacional por meio dessa oferta de produtos e serviços de informação? 


\section{GESTÃO DA INFORMAÇÃO E DO CONHECIMENTO NAS ORGANIZA- ÇÕES COM ORIENTAÇÃO DE MAR- KETING}

Admite-se que, embora bibliotecas

e outras unidades de informação/documentação devessem estar envolvidas com ambos os processos de gestão, o da informação e o do conhecimento. Entretanto, essas unidades de informação ainda não estão assumindo plenamente a gestão do conhecimento.

A socialização do conhecimento dentro do ambiente organizacional deve ser uma prioridade. O mapeamento dos fluxos da informação e a detecção de ilhas e gargalos são os primeiros passos na longa caminhada até a efetiva gestão. Por tratar-se de um processo que envolve a participação humana, o seu acompanhamento deve ser constante $e$ as possibilidades de ajuste devem considerar o elemento humano.

Isto requer mudança no comportamento profissional; confiança na prestação de serviço de qualidade e melhor imagem do setor de informação pela sociedade.

As bibliotecas e demais unidades de informação não poderão continuar a pensar em oferecer seus produtos e serviços apenas no seu ambiente tradicio- nal, limitadas ao espaço físico da localização do seu prédio. Elas precisam também estar presentes na Internet, representadas pelos seus websites.

Porém, a nova web é fundamentalmente diferente tanto na sua arquitetura quanto na sua aplicação. Em vez de imaginar um jornal digital, pense em uma tela compartilhada onde cada borrão de tinta feito por um usuário fornece uma imagem mais rica, que poderá ser modificada ou desenvolvida pelo próximo usuário. Estejam as pessoas criando, compartilhando ou socializando, a nova web significa, sobretudo, participar em vez de receber passivamente informações.

Em que isso difere da Internet inicial? Pense na primeira interação da web como um jornal digital. Você podia abrir as suas páginas e observar as suas informações, mas você não podia modificálas ou interagir com elas. Você raramente podia se comunicar de forma significativa com os autores, a não ser através de um e-mail para o editor.

A conclusão é a seguinte, para se fazer representar na Internet, o website da biblioteca não poderá ser imutável e autônomo. A nova web cada vez mais se parece com uma biblioteca cheia de componentes que interagem e falam uns com os outros. As pessoas estão desenvolvendo softwares, bancos de dados e 
websites não apenas para satisfazerem seus objetivos, mas também para que possam ser usados de várias maneiras que os seus próprios criadores desconheciam ou que não haviam planejado. Isso torna muito fácil criar novos serviços via web a partir desses componentes existentes, juntando-os em novas combinações.

Portanto, um novo tipo de biblioteca deve surgir. Uma biblioteca que abra suas portas para o mundo; inove em conjunto com todos, sobretudo com os seus usuários, compartilhe recursos que antes eram guardados a sete chaves, utilize o poder da colaboração em massa e se comporte como biblioteca verdadeiramente global. Essas bibliotecas estarão liderando importantes mudanças e reescrevendo muitas regras para o acesso e compartilhamento da informação para geração de conhecimento. Essa biblioteca irá além dos seus próprios meios para semear inovação e criar valor.

Os bibliotecários e profissionais da informação necessitam prestar atenção, saber como os indivíduos se comportam na busca e recuperação das informações que necessitam. Muitos usuários estão sempre conectados e ficam chateados quando estão fora da Rede. Provavelmente, é possível que eles não sintam necessidade de usar a biblioteca e, por- tanto, não a considerarão como algo importante e visível.

É preciso conhecer melhor os usuários como consumidores de informação para atendê-los satisfatoriamente. Afinal, é por causa deles e para eles que a biblioteca ou unidade de informação existe e é em função deles que sobrevive. Para que isto seja uma realidade, esses profissionais deverão interagir com profissionais de outras áreas, somando esforços para melhorar seu desempenho e o das bibliotecas e unidades de informação. Precisam entender o negócio da informação, como agentes sociais responsáveis pela oferta de produtos e serviços de informação da biblioteca enquanto provedora de informação no mercado da informação. Não basta que a biblioteca do futuro seja digital. Para sobreviver nesse contexto, a biblioteca precisa atuar como uma empresa prestadora de serviços de informação orientada para o marketing.

O profissional da informação deve ter consciência disso para saber como aplicar os ensinamentos da sua formação profissional tradicional de forma nada tradicional na prática da gestão da informação e do conhecimento nas organizações com a orientação de marketing. Estamos na era da conectividade e é preciso chegar ao usuário onde e como ele 
quer. Novos serviços, sistemas de referência digital e novas estruturas de dados precisam ser desenvolvidos para ajudar o bibliotecário a vencer esse desafio. Nesse sentido, o profissional deve saber tornar o usuário um parceiro colaborador e também aprender a envolver os usuários nos processos de planejamento e produção dos novos produtos e serviços de informação com valor agregado, capazes de atender satisfatoriamente às novas demandas dos consumidores da sociedade da informação e do conhecimento. A participação do usuário no processo de criação da oferta de informação é a oportunidade para o profissional conhecer e se manter atualizado sobre as necessidades e interesses da demanda informacional dos usuários da biblioteca e das demais unidades de informação.

O desafio do bibliotecário é o de atender usuários que não têm tempo nem paciência para ir a bibliotecas. $\mathrm{O}$ bibliotecário não precisa obrigar o usuário $a$ ir até a informação ou até a biblioteca. As bibliotecas precisam se adequar para enfrentar a concorrência das ferramentas de busca na Internet, como Google e o Yahoo, para citar apenas algumas delas. $\mathrm{Na}$ realidade, o Google recebe mais consultas em um dia e meio do que todas as bibliotecas americanas em um ano.
O bibliotecário e o profissional da informação também devem estar preparados para utilizar o potencial das TICs em prol da criação, compartilhamento e uso do conhecimento, a partir da prática dos processos de organização, catalogação, classificação, indexação, registros, armazenamento, disseminação, recuperação, que tornem a informação disponível para ser acessada e utilizada pelos interessados. Cabe a esses profissionais prestar serviços e oferecer produtos informacionais capazes de atender a demanda e as necessidades de informação dos usuários em suas buscas para recuperar a informação que satisfaça seu interesse.

Nessa perspectiva, é exigido o constante aprimoramento do desempenho profissional dos prestadores de serviços de informação. Sob esse aspecto, torna-se importante a preocupação com a educação continuada de toda a equipe, inclusive a do gerente. É preciso que haja um plano de desenvolvimento de recursos humanos que favoreça a participação em eventos e, em especial, em cursos, treinamentos, visitas e estágios que levem a atualização e o domínio do conhecimento de marketing e das habilidades exigidas para o exercício profissional no mercado da informação. 
Entretanto, será que de um modo geral, os bibliotecários e os profissionais da informação entendem que a biblioteca e demais unidades de informação estão inseridas no mercado, onde atuam clientes, fornecedores, mantenedores, consumidores ou usuários interessados em produtos ou serviços? Será que se dão conta que nesse mesmo mercado também atuam outros provedores de informação que podem satisfazer a demanda informacional no âmbito do "negócio da informação"?

Na visão sistêmica da biblioteca do futuro, a informação continuará a ser o insumo básico de entrada ao mesmo tempo em que se constituirá no insumo básico de saída. Muitos fatores terão influência no ciclo documentário em cada organização, de acordo com a sua tipologia e da influência das mudanças que são constantes em todos os cenários. Mas, para entender o negócio da informação e o seu mercado, o profissional deverá sempre:

- Entender as novas formas de colaboração em massa;

- Assumir a postura de aprender a aprender e viver;

- Estar atualizado na utilização de novas tecnologias;
- Investigar, permanentemente, os novos nichos de mercado da informação;

- Inovar as técnicas de segmentação de mercado;

- Identificar o novo perfil do consumidor da informação;

- Buscar novos produtos que proporcionem vantagens em relação à concorrência;

- Criar e manter serviços personalizados aos usuários/clientes/consumidores;

- Posicionar produtos e serviços em condições compatíveis com a imagem da unidade de informação;

- Entender novos modelos de distribuição no ambiente eletrônico;

- Conhecer o novo papel da comunicação, interagindo com os profissionais desta área;

- Descobrir o modelo ideal para promover os produtos e serviços oferecidos;

- Aprimorar o relacionamento com a clientela;

- Envolver os usuários no planejamento e produção de produtos e serviços de informação;

- Visualizar modalidades para estabelecer parcerias com a comunidade, governo, órgãos de classe e agências de fomento; 
- Moldar um novo e atualizado profissional para o atendimento e relacionamento com os diversos públicos;

- Investir em controles para aprimorar desempenhos da equipe, do gerente e das metodologias de trabalho. (AMARAL, 1996).

Trata-se da questão de o profissional de informação aceitar sua responsabilidade social de agente de transformação da sociedade, que deve ser bem informada para ser capaz de gerar o conhecimento necessário ao desenvolvimento econômico, cultural e social da sociedade brasileira. É preciso ousar e utilizar a criatividade, liderança, capacidade de inovação na gestão da informação e do conhecimento orientada para o marketing. Além disso, os profissionais da informação, excepcionalmente os gerentes, devem aprender a converter idéias em realidade. Devem ampliar a capacidade de dialogar, exercitando a argumentação, que facilita o processo de negociação, principalmente com os mantenedores da unidade de informação.

\section{CONSIDERAÇÕES FINAIS}

A proposta de atuação da biblioteca do futuro como organização orientada para o marketing, de modo a contribuir para o desenvolvimento dos processos de gestão da informação e do conhecimento é inovadora. Porém, essa é uma pequena mudança de paradigma para os bibliotecários e profissionais da informação, que estão acostumados a ajudar as pessoas a encontrar uma informação específica. Na mineração de dados e no gerenciamento do conhecimento, esses profissionais examinam vastos campos de dados em busca de tendências e padrões. Eles precisam aplicar essas habilidades tradicionais de forma totalmente não tradicional para realizar a gestão da informação e a gestão do conhecimento com a orientação de marketing.

Será que os profissionais que atuam em bibliotecas e demais unidades de informação estão preparados para enfrentar o desafio profissional a que estão submetidos, quer queiram, quer não?

\section{REFERÊNCIAS}

AMARAL, S. A. Marketing e desafio profissional em unidades de informação. Ciência da Informação, Brasília, v. 25, n. 3, p. 330-336, 1996.

AMARAL, S. A. Marketing da informação: entre a promoção e a comunicação integrada de marketing. Informação e Sociedade: Estudos, João Pessoa, v. 18, n. 1, p. 31-44, jan./abr. 2008.

AMERICAN MARKETING ASSOCIATION. Dictionary of Marketing Terms. 2004. Disponível em: 
$<$ http://www.marketingpower.com/mgdictionary-view1862.php >. Acesso em: 20 set. 2007.

BEIJERSE, R. P. Knowledge management in small and medium-sized companies: knowledge management for entrepreneurs. Journal of Knowledge Management, Bingley, v. 4, n. 2, p. 162-179, 2000.

BORGES, M. E. N. A informação como recurso gerencial das organizações na sociedade do conhecimento. Ciência da Informação, Brasília, v. 24, n. 2, p. 181188, 1995.

BORKO, $\mathrm{H}$. Information science: what is it? American documentation, Washington, v. 19 , n. 1, p. 3-5, 1968.

CORNELSEN, J. M. Gerência da informação como recurso estratégico nas empresas: o caso Eliane Paraná. 1999. Tese. (Mestrado em Comunicação Social) - Escola de Comunicação e Artes da Universidade de São Paulo, Universidade Federal de São Paulo, São Paulo. p. 926.

$\mathrm{CHOO}, \mathrm{C} . \mathrm{W}$. Research in information and Knowledge Management. Brasília: PUC/DF, 29 abr. 2006. Palestra.

DAVIS, K. Human relations at work: the dynamics of organizational behavior. 3.ed. Nova York: International Student Edition, 1967.

LE COADIC, Y. A ciência da informação. Brasília: Briquet de Lemos, 1996.

KOTLER, P. Administração de marketing. São Paulo: Prentice Hall, 2000

THAYER, L. Princípios de comunicação na administração: comunicação e sistemas de comunicação na organização da administração e relações internas. São Paulo: Atlas, 1972.

\section{Title}

Information and Knowledge Management in Organizations and the Marketing Guidance.

\begin{abstract}
The article presents some aspects of Communication, Administration and information technology related to information and knowledge management processes within the Information Science scope, emphasizing the information and knowledge importance for the information and knowledge society. It discusses the importance of understanding the information business in the marketing point of view and it shows in a schematic way the information products and services that are offered in both traditional and web environment, where several social actors of information business are involved. The marketing principles that are crucial to be follow by marketing orientated information units are presented, as a suggestion for the future library survival, being aware of new consumers' requirements and expectations.
\end{abstract}

\section{Keywords}

Information management, knowledge management, marketing guidance, information offer, information demand.

\section{Titulo}

Gestión de información y del conocimiento en las organizaciones y la orientación de marketing

\section{Resumen}

El artículo comenta los aspectos de la comunicación, de la administración y de la tecnología de la información en relación a los procedimientos de gestión de información y de gestión del conocimiento, en visión de las Ciencias de la Información, enfatizando la importancia de la información y del conocimiento en el contexto de la sociedad de la información y del conocimiento. Discute la necesidad de entender el negocio de la información en visión del marketing y muestra un esquema para el suministro de productos y 
servicios de información en el medio ambiente tradicional y la web en el contexto del mercado de la información, donde actuan los diversos actores sociales del negocio de la información. Presenta los principios de marketing a seguir por la unidad de información orientada a la comercialización, como una sugerencia para la supervivencia de la biblioteca del futuro, de conformidad con los requisitos exigidos por los nuevos consumidores de la sociedad de la información y del conocimiento.

\section{Palabras clave}

Gestión de información; Gestión de los conocimientos; Orientación de Marketing; Oferta de información; Demanda de información.

Recebido em: 12.10.2008

Aceito em: 14.11.2008 